\title{
Erratum to: Spatially explicit uncertainty modeling of zoonotic pathogen distribution: a case of Listeria monocytogenes in New York State, USA
}

\author{
Rita Mwima ${ }^{1}$ - Anthony Gidudu ${ }^{2}$ - Allan Mazimwe ${ }^{3}$ - Arika Ligmann-Zielinska ${ }^{4}$. \\ Samuel Majalija ${ }^{5} \cdot$ Margaret Khaitsa $^{6} \cdot$ John David Kabasa $^{7} \cdot$ Peter Bergholz $^{8}$
}

Published online: 17 April 2017

(C) Società Italiana di Fotogrammetria e Topografia (SIFET) 2017

Erratum to: Appl Geomat (2017) 9:27-41

DOI 10.1007/s12518-016-0177-4

The original version of this article unfortunately contained mistakes.

The Listeria monocytogenes study used as input for modeling in this article was obtained from Cornell University. We did not provide acknowledgment of the source and we neglected to cite a previous paper that describes some analysis of these data. We apologize for this oversight and publish the following correction to our Materials and Methods, Acknowledgments, and References section.

The online version of the original article can be found at http://dx.doi. org/10.1007/s12518-016-0177-4

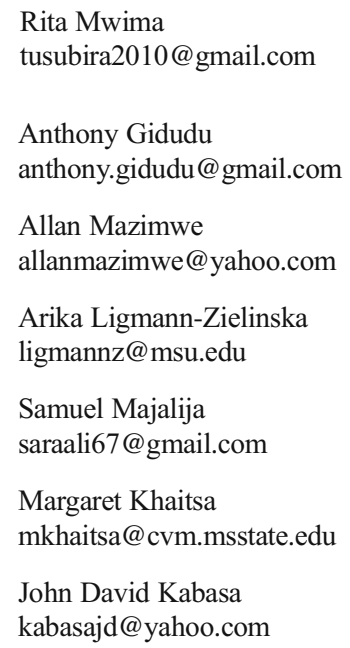

\section{Materials and methods (page 3; first paragraph)}

The initial survey for Listeria monocytogenes and other Listeria spp. was conducted as described in Chapin et al. (2014). We replicated the random forest analysis of environmental distribution by independently obtaining and processing spatial and meteorological GIS predictor data (Table 2). The results obtained in this article using the mean decrease in Gini index criterion were comparable to those in Fig. 2A of Chapin et al. (2014). We used the replicated random

Peter Bergholz

peter.bergholz@ndsu.edu

1 Makerere University, Kampala, Uganda

2 College of Engineering, Design, Art and Technology (CEDAT), Makerere University, Kampala, Uganda

3 Makerere University, CEDAT, Kampala, Uganda

4 Michigan State University (USA), Lansing, MI, USA

5 College of Veterinary Medicine, Animal resources and Biosecurity (CoVAB), Makerere University, Kampala, Uganda

6 Mississippi State University, Starkville, MS, USA

7 College of Veterinary Medicine, Animal Resources and Biosecurity, Makerere University, KampalaUganda, Uganda

8 North Dakota State University, Fargo, ND, USA 
forest analysis results for the presented habitat suitability and spatial uncertainty modeling reported in this article.

Acknowledgements We thank Martin Wiedmann, Laura K. Strawn and Travis K. Chapin for the use of their data on presence of Listeria monocytogenes in environmental samples from New York natural areas.

\section{References}

Chapin TK, Nightingale KK, Worobo RW, Wiedmann M, Strawn LK (2014) Geographical and meteorological factors associated with isolation of Listeria species in New York State produce production and natural environments. J Food Prot 77:1919-1928 